\title{
Sistema de ensino de Singapura e plano de ação para o modelo híbrido
}

\author{
Singapore education system and action plan \\ for the hybrid model \\ Sistema educativo de Singapur y plan de \\ acción para el modelo híbrido
}

ALINE FonsECA GOMES

\section{Resumo}

O ensino híbrido ao combinar a aprendizagem por desafios, problemas e jogos possibilita aos alunos maior engajamento, vislumbrando a utilização de metodologias ativas de aprendizagem e da sala de aula invertida. Assim, este estudo objetivou de forma geral compreender como os princípios de um modelo de ensino de excelência, baseados no o Programa Internacional de Avaliação de Alunos PISA, podem ser utilizados pelo sistema educacional brasileiro, ao se desenvolver um plano de ação para o ensino híbrido. Foi escolhido o sistema de ensino de Singapura devido à representatividade ao longo dos anos do PISA e aos rankings alcançados nos últimos PISA, além de ser conhecido como um dos maiores centros financeiros do mundo, tendo investido em educação. Utilizou-se por metodologia uma pesquisa exploratória e ensaio teórico com análise dos dados de natureza qualitativa, ao se estudar o sistema de ensino de Singapura. Por resultados tem-se que através do plano de ação para implementação no ensino híbrido e a partir das variáveis da profissão docente, acredita-se que é possível desenvolver uma prática reflexiva, construir conexões e permitir que os docentes reflitam, compartilhem e planejem seus próprios objetivos de aprendizagem, além disso, faltam programas de formação continuada para os educadores brasileiros, disponibilizados a partir

\footnotetext{
a Instituto Federal de Educação, Ciência e Tecnologia Baiano, Teixeira de Freitas, BA, Brasil. Doutora em Desenvolvimento Regional e Urbano, e-mail: aline.gomes@ifbaiano.edu.br
} 
das instituições de ensino demandantes para valorizar os professores de forma efetiva, promovendo o seu desenvolvimento profissional.

Palavras-chave: Aprendizagem. Metodologias. Avaliação. Educacional.

\begin{abstract}
Hybrid teaching combining learning by challenges, problems and games allows students to be more engaged, envisioning the use of active learning methodologies and the inverted classroom. Thus, this study aimed in general to understand how the principles of an excellent teaching model, based on the International Student Assessment Program - PISA, can be used by the Brazilian educational system, when developing an action plan for teaching hybrid. The education system in Singapore was chosen due to its representativeness over the years of PISA and the rankings achieved in the last PISA, in addition to being know as one of the largest financial centers in the world, having invested in education. An exploratory and theoretical essay with qualitative data analysis was used by methodology, when studying the education system of Singapore. For results we have that through the action plan for implementation in hybrid teaching and from the variables of the teaching profession, it is believed that it is possible to develop a reflective practice, build connections and allow teachers to reflect, share and plan their own learning objectives, in addition, there is a lack of continuing education programs for Brazilian educators, made available from demanding educational institutions in order to value teachers effectively, promoting their professional development.
\end{abstract}

Keywords: Learning. Methodologies. Assessment. Educational.

\title{
Resumen
}

La enseñanza híbrida que combina el aprendizaje por desafíos, problemas y juegos permite que los estudiantes se involucren más, visualizando el uso de metodologías de aprendizaje activo y el aula invertida. Así, este estudio tuvo como objetivo en general comprender cómo los principios de un modelo de enseñanza excelente, basado en el Programa Internacional de Evaluación de Alumnos - PISA, pueden ser utilizados por el sistema educativo brasileño, al desarrollar un plan de acción para la enseñanza híbrida. El sistema educativo de Singapur fue elegido por su representatividad a lo largo de los años de PISA y las clasificaciones logradas en el último PISA, además de ser conocido como uno de los centros financieros más grandes del mundo, habiendo invertido en educación. Se utilizó una investigación exploratoria y ensayo teórico con análisis de datos cualitativos por metodología, al estudiar el sistema educativo de Singapur. Por resultados tenemos que a través del plan de acción para la implementación en la enseñanza híbrida y a partir de las variables de la profesión docente, se cree que es posible desarrollar una práctica reflexiva, construir conexiones y permitir que los docentes reflexionen, compartan y planifiquen su propio aprendizaje. objetivos, además, se carece de programas de educación continua para los educadores brasileños, a 
disposición de las instituciones educativas exigentes, con el fin de valorar eficazmente a los docentes, promoviendo su desarrollo profesional.

Palabras clave: Aprendizaje. Metodologias. Evaluación. Educativo.

\section{Introdução}

O ensino híbrido constitui-se de práticas inovadoras a respeito de diversas variáveis presentes no projeto político-pedagógico dos cursos. De acordo com Bacich, Tanzi Neto \& Trevisani (orgs.) (2015), as mais importantes dimensões são: ênfase no projeto de vida de cada aluno; ênfase nos valores e competências amplas, inclusive de conhecimento socioeducacionais; e equilíbrio entre as aprendizagens individual e grupal.

A educação no sentido de promover o aprendizado utiliza de canais, tais como o sistema de ensino, seja este presencial ou híbrido, por exemplo. Dessa maneira, este estudo sobre um sistema de ensino de excelência internacional possibilitou o desenvolvimento de um plano de ação para implementação em cursos que utilizam o ensino híbrido, sendo este o foco do trabalho.

A fim de identificar soluções para os desafios do processo de ensinoaprendizagem a partir da suspensão das aulas, na rede pública de ensino, com a pandemia do Covid-19 e para propor melhorias no próprio sistema de ensino, evidenciou-se que, na pós-pandemia, o ensino deverá ser efetivado no modelo híbrido, daí surgiu o interesse em pesquisar sobre sistemas de ensino de reconhecido sucesso no mundo buscando identificar qual ou quais desses sistemas de ensino têm recebido as maiores avaliações por meio de mensuração de desempenho, para que então fossem estudados tais sistemas melhor ranqueados.

Nesse sentido, com este estudo sobre sistema de ensino foi possível compreender que se trata de um dispositivo pedagógico-administrativo, o qual define os processos e procedimentos no âmbito educacional. Em convergência, apresentase que o ensino no Brasil está organizado e estruturado de acordo com a Lei de Diretrizes e Bases da Educação — LDB n. ${ }^{\circ}$ 9.394/96, que estabelece quais são os níveis e modalidades de ensino e que regulariza o sistema de educação brasileiro com base nos princípios presentes na Constituição. 
Logo, adotou-se por problemática a seguinte: De que forma pode-se utilizar um modelo de educação híbrido a partir dos princípios adotados por um dos melhores sistemas de ensino do mundo de acordo com ranking do Programa Internacional de Avaliação de Alunos — PISA? Objetivando de forma geral compreender como os princípios de um modelo de ensino de excelência, baseados no PISA, podem ser utilizados pelo sistema educacional brasileiro, ao se desenvolver um plano de ação para o ensino híbrido.

Ao pesquisar sobre o tema avaliação do desempenho escolar foi possível identificar o PISA, o qual se trata de uma rede mundial que compara os resultados dos países ao avaliar os conhecimentos e as habilidades dos discentes. Segundo dados do Instituto Nacional de Estudos e Pesquisas Educacionais Anísio Teixeira — INEP, através dos resultados do PISA é possível aprender com as políticas e práticas aplicadas em outros lugares e, assim, formular políticas e programas educacionais visando à melhora da qualidade e da equidade dos resultados de aprendizagem.

\begin{abstract}
O Programa Internacional de Avaliação de Estudantes (Pisa), tradução de Programme for International Student Assessment, é um estudo comparativo internacional realizado a cada três anos pela Organização para a Cooperação e Desenvolvimento Econômico (OCDE). O Pisa oferece informações sobre o desempenho dos estudantes na faixa etária dos 15 anos, idade em que se pressupõe o término da escolaridade básica obrigatória na maioria dos países, vinculando dados sobre seus backgrounds e suas atitudes em relação à aprendizagem, e também aos principais fatores que moldam sua aprendizagem, dentro e fora da escola (INEP, 2020).
\end{abstract}

Ainda segundo o INEP (2020), o PISA avalia três domínios: leitura, matemática e ciências, sendo que a cada edição é avaliado um domínio principal, ou seja, os discentes respondem a um maior número de itens no teste dessa área do conhecimento e os questionários se concentram na coleta de informações relacionadas à aprendizagem nesse domínio. Além disso, também é avaliado: Resolução de Problemas, Letramento Financeiro e Competência Global.

Os dados do PISA compreendem as percepções dos discentes, dos docentes e dos gestores educacionais, favorecendo a visão sistêmica sobre o processo educacional, daí a escolha por estes dados como base para esta pesquisa. Em contrapartida, a Pesquisa Internacional de Ensino e Aprendizagem (TALIS), também desenvolvida pela OCDE, é direcionada apenas aos professores e líderes escolares, 
abordando as condições de trabalho e ambientes de aprendizagem nas escolas com a finalidade de auxiliar os países participantes a enfrentar diversos desafios.

Convêm ressaltar que um sistema de ensino está inserido em um contexto mais amplo que envolve implicações econômicas, políticas, culturais, históricas, com base em Soares e Soares (2017). Assim, apesar de se reconhecer as inúmeras diferenças entre os países bem ranqueados no PISA e a realidade brasileira, acredita-se que este estudo pode servir de base para o desenvolvimento e a implementação de soluções educacionais que podem ser replicadas na nossa realidade.

Diante do exposto, foi escolhido o sistema de ensino de Singapura para realizar a pesquisa, devido à representatividade ao longo dos anos do PISA, e aos rankings alcançados nos últimos PISA. Em conformidade ao elevado índice educacional de Singapura, a Embaixada de Portugal em Singapura (2020) descreve que desde a sua independência e a partir dos anos 70, Singapura tem seguido uma política de captação de investimento estrangeiro, especialmente de multinacionais, na ausência de corrupção como valor social e em elevados níveis de educação e proteção ambiental, possui uma excelente rede de comunicações e de um sistema fiscal bastante atrativo, além de Singapura ser hoje o líder no rank mundial de liberdade econômica e em competitividade, um dos maiores centros financeiros do mundo que investe largamente na educação da população, conforme apresentado na metodologia deste artigo.

Nesse sentido, este estudo teve por objetivos específicos: expor o sistema de ensino de Singapura, por meio da coleta e análise dos dados dos documentos e informações dos órgãos oficiais da área de educação; apresentar o modelo de ensino híbrido; desenvolver um plano de ação que possa ser utilizado no ensino híbrido por instituições educacionais brasileiras.

\section{Sistema de ensino de Singapura}

De acordo com dados do Governo de Singapura (2020), sob a responsabilidade do Ministério da Educação está a Academia dos Professores de Singapura, que oferece desenvolvimento profissional e treinamento para professores em serviço, líderes de escolas de nível médio, educadores aliados e funcionários 
executivos e administrativos, além de impulsionar a liderança pedagógica como um ponto focal, utilizando-se de uma plataforma para compartilhamento de liderança do professor.

A formação dos professores de Singapura era restrita até 1950, pois após esta data, no período pós-guerra, foi criado o Teachers Training College — TTC com cursos certificadores em educação. Em 1971, a Universidade de Singapura também passou a preparar os estudantes para profissionalizá-los por meio de um Diploma de Educação e, em 1973, institui-se o Instituto de Educação. Em 1991, com a fusão do instituto e da Faculdade de Educação Física surgiu o National Instituto of Education NIE (SILVA, 2011).

O currículo do Instituto Nacional de Educação de Singapura fundamenta-se em seis eixos básicos, tais como: estudos educacionais, estudos curriculares, domínio da matéria, cursos essenciais, habilidade discursiva e habilidades práticas. Também conforme Silva (2011) destaca-se que a carreira docente é altamente valorizada do ponto de vista do prestígio social e financeiro, incentivando os professores a desenvolverem suas competências.

Apresenta-se que as atividades desenvolvidas na Academia dos Professores impulsionam o desenvolvimento profissional por meio de comunidades em rede, elevando o nível de prática profissional em sala de aula e especialização em todo o sistema. Segundo Moreira e Lopes (2019): o caminho trilhado pelo país asiático para chegar ao topo da Educação mundial e passa por uma forte organização, em que todas as entidades envolvidas na oferta da Educação pública de Singapura estão alinhadas entre si, formando um grande ecossistema.

Em relação às supracitadas entidades, as principais são: Ministry of Education, National University of Singapore, National Institute of Education (único órgão responsável pela formação de professores em todo o país), Institute of Technical Education, Academy of Singapore Teachers. Com o foco no domínio do conhecimento público da teoria, da pesquisa e de boas práticas na sala de aula pelos professores, o Sistema de Ensino de Singapura representa um modelo em crescimento a partir de aprendizagem em rede.

A Singapore Teaching Practice (STP) é um modelo que torna explícito como o ensino e a aprendizagem eficazes são alcançados nas escolas de Singapura. Ancorado na noção de que o ensino é uma profissão, o STP baseia-se nas crenças dos educadores 
de Singapura sobre como os alunos aprendem e os professores ensinam. É representado na forma de uma orquídea para refletir o contexto de Cingapura dentro do qual praticamos nosso ofício e buscamos melhorar nossa prática como uma fraternidade colaborativa (ACADEMY OF SINGAPORE TEACHERS, 2021).

Nesse sentido, a prática de ensino relaciona-se com: alunos compreensivos e aprendizagem, ensino compreensivo, assunto e objetivos compreensíveis, objetivando as práticas pedagógicas por meio de uma filosofia curricular de Singapura, representada pelo símbolo nacional de Singapura que é uma orquídea, conforme Figura 1 a seguir:

Figura 1 - Prática de Ensino de Singapura

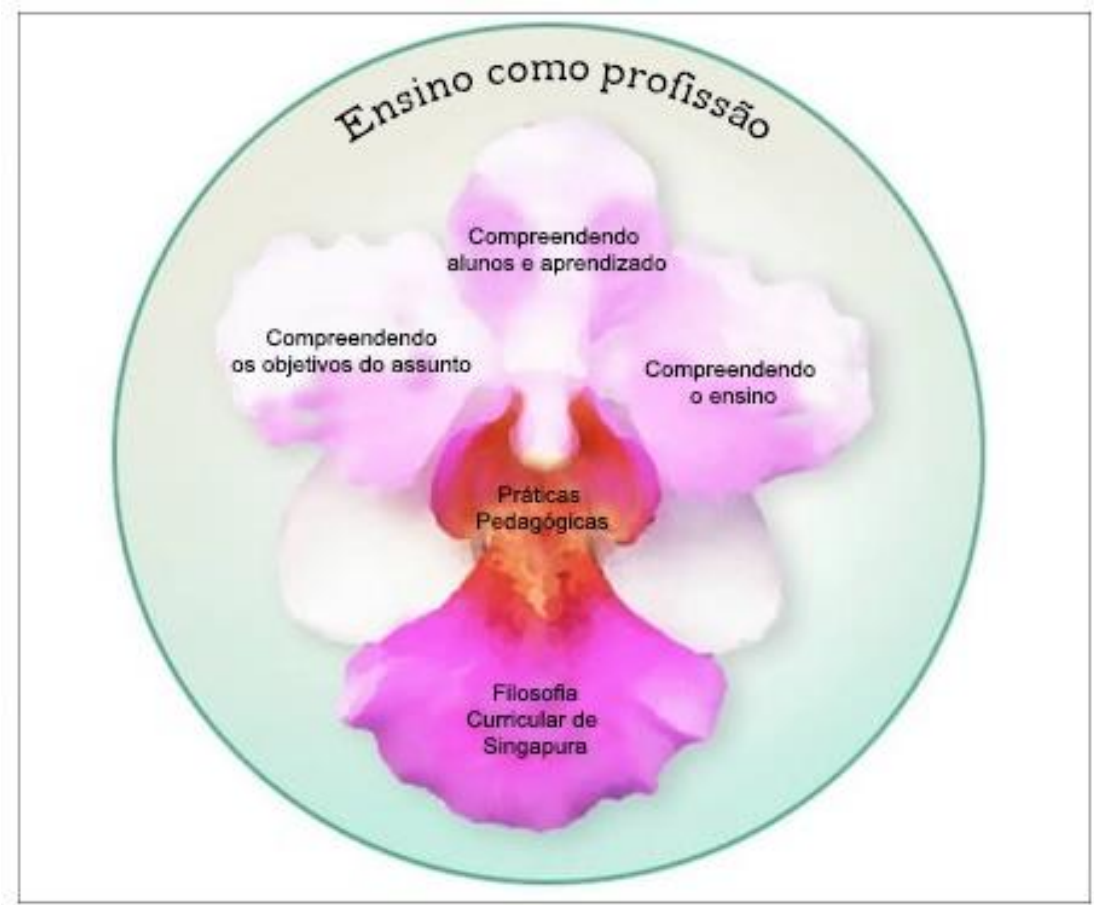

Fonte: Adaptado de Academy of Singapore Teachers (2021).

Assim, as práticas de ensino focalizam as competências individuais em prol da coletividade. Sobre o comportamento dos professores, o sistema educacional de Singapura trata de cinco variáveis ou facetas da profissão docente, tais como: 1. a filosofia da educação para educadores que se relaciona com as crenças e pressupostos básicos da prática profissional; 2. os resultados desejados da educação que orienta as políticas, programas e práticas educacionais e escolares; 3. a visão do professor em busca da excelência profissional e que relaciona-se com as motivações individuais; 4. 
o compromisso dos professores em manter altos padrões na prática profissional e que relaciona-se diretamente com a qualidade do processo de ensino-aprendizagem; 5. um guia que explicita as crenças tácitas e codifica as práticas como um manual a ser seguido, de forma inclusive a padronizar o processo de ensino (ACADEMY OF SINGAPORE TEACHERS, 2021).

Sobre a formação dos professores para o século 21, portfólios digitais foram introduzidos pela primeira vez no NIE em 2010 para fortalecer o nexo teoria e prática da aprendizagem e do ensino em sala de aula, bem como para ajudar os alunosprofessores a agregar e integrar sua aprendizagem, apoiando e fornecendo aos alunosprofessores conhecimentos, habilidades, atitudes e ferramentas para indagar sobre seu próprio aprendizado e práticas profissionais (MCCONNELL, 2013).

Assim, as diferentes facetas da profissão docente são abordadas nos cursos da Academia de Professores, e focalizam um modelo de crescimento em seu Centro de Excelência em Ensino e Aprendizagem e através de investigações críticas sobre o desenvolvimento profissional dos educadores. Dentro do modelo de crescimento do professor busca-se adotar comportamentos tais como: aprendizagem autônoma, valorizando competências profissionais e técnicas; contribuições ativas, transformando o educador em líder; cidadão preocupado, consciente de seu papel, valorizando inclusive a diversidade; pessoa confiante, segura e com domínio do conhecimento, a fim de desenvolver as atividades com base em princípios e práticas educacionais que engajem os alunos por meio de uma investigação crítica no desenvolvimento profissional.

A Investigação Crítica no Desenvolvimento Profissional é uma abordagem sistemática que os professores adotam para refletir e melhorar sua prática. A Investigação Crítica envolve uma área de investigação em sala de aula com o objetivo de refinar as práticas de sala de aula e aprimorar o aprendizado do aluno. Durante o processo de investigação crítica, os professores identificam as necessidades e lacunas de aprendizagem, geram perguntas, desenvolvem ideias, examinam estratégias, reúnem evidências e analisam dados para melhorar o ensino e a aprendizagem em sala de aula. (ACADEMY OF SINGAPORE TEACHERS, 2021).

Assim, ainda conforme a Academia de Professores de Singapura, com a investigação crítica será possível: aprender a adotar uma abordagem intencional na geração de perguntas pelos docentes, o que se pode evidenciar a resolução de 
problemas pelos discentes; desenvolver uma abordagem sistemática na coleta de informações e análises, favorecendo inclusive o letramento financeiro; promover o engajamento na prática reflexiva, que integra teoria, pesquisa e prática, e que pode estabelecer competências globais, por exemplo; além de buscar o refinamento das práticas de sala de aula de forma a influenciar positivamente no aprendizado dos alunos.

Segundo Elos Educacional (2019) o Ministério da Educação de Singapura, as escolas e as instituições que formam os professores têm suas práticas pautadas por um currículo que intencionalmente visa responder à demanda de preparar os alunos para a inclusão social, garantindo assim maior capacidade de inserção e de transformação social.

Destaca-se que para se tornar professor em Singapura é necessário fazer um curso para obter o referido diploma no Instituto Nacional de Educação e, em seguida, pode-se realizar os cursos específicos, como um treinamento continuado para desenvolver competências na Academia de Professores, o que fará com que o professor seja inserido em uma comunidade de aprendizagem, valorizando e aprimorando suas práticas de ensino.

Exemplificando, um curso do Instituto Nacional de Educação de certificado de ensino e aprendizagem para comunidades educacionais pressupõe o fornecimento de conhecimento pedagógico básico para educadores em centros de educação de base comunitária, de modo a desempenhar suas funções e deveres no contexto de sua sala de aula. Tal curso visa fornecer conhecimentos básicos para os participantes em pedagogia e aprendizagem, avaliação e habilidades de gerenciamento de sala de aula através de: ensino e abordagens pedagógicas; desenho e entrega da aula; avaliação e monitoramento na avaliação da aprendizagem do aluno; habilidades de gerenciamento de sala de aula; entendendo o Aluno (NIE, 2021).

O sistema de ensino de Singapura também atua a partir do estabelecimento de comunidades de aprendizagem profissional, que visam fomentar uma cultura de excelência profissional nas escolas de todo o sistema. As comunidades de aprendizagem em rede são equipes de professores de diferentes escolas trabalhando e aprendendo de forma colaborativa para examinar e refletir sobre sua prática. 
Para Jackson \& Temperley (2006) existem seis vertentes para a estrutura básica das comunidades de aprendizagem em rede, tais como: aprendizagem do aluno um enfoque pedagógico; aprendizagem de adultos — comunidades de aprendizagem profissional são uma aspiração fundamental; aprendizagem de liderança - em todos os níveis; aprendizagem organizacional — novas normas de aprendizagem organizacional; aprendizagem escola a escola - aprendizagem em rede; aprendizagem rede a rede — aprendizagem lateral do sistema.

Segundo a Fundação Lemann (2020) sobre o sistema educacional de Singapura, a valorização da formação dos professores é efetiva, tanto a inicial quanto a continuada e o Ministério da Educação é o responsável por selecionar os futuros professores, considerando tanto habilidades técnicas quanto sua paixão por ensinar. Quando os professores são selecionados passam a estudar no National Institute of Education, a única instituição que forma professores no país.

Os programas de Preparação Inicial de Professores (ITP) na NIE preparam você para uma carreira como professor. O programa desenvolve o conhecimento e as habilidades dos alunos-professores exigidos dos professores para atender com competência as demandas e os desafios de uma carreira docente dinâmica (NATIONAL INSTITUTE OF EDUCATION, 2021).

No Instituto Nacional de Educação de Singapura existem programas iniciais de preparação de professores para professores que lecionarão em escolas primárias ou secundárias. Ao concluir um curso com duração média de oito meses a dois anos, os professores diplomados são capazes de aplicar abordagens baseadas em evidências para ajudar os alunos da escola a desenvolverem seus pontos fortes para lidar eficazmente com os problemas da vida. Segundo Abreu (2017), em Singapura, há um claro investimento na formação inicial e contínua dos professores e também a disponibilização de bons materiais didáticos.

O Ministério da Educação de Singapura aceita apenas professores com elevada qualificação. Assim, os contratos de trabalho para os professores são assinados por um período mínimo de três anos, estando previstas penalidades caso esse contrato seja rescindido antes do prazo estabelecido. Além disso, durante a formação inicial de professores, os alunos universitários são colocados em contexto de sala de aula com o intuito de experienciarem o que significa ser professor (ABREU, 2017). 
Assim, percebe-se que o sistema de ensino de Singapura envolve teoria, pesquisa e boas práticas pelos professores, desenvolvendo treinamentos que visam o compartilhamento de experiências entre eles. De acordo com McConnell (2013) o desenvolvimento profissional, que envolve os professores na investigação educacional por meio de comunidades de aprendizagem profissional colaborativa é eficaz para melhorar a instrução e o desempenho dos alunos. Dessa maneira, tanto a valorização quanto a formação dos professores pode ocorrer na prática, impulsionando, assim, o processo de aprendizagem dos alunos.

\section{O ensino híbrido}

O conceito de ensino híbrido trata da convergência de dois modelos de aprendizagem: o presencial e o on-line utilizando-se das tecnologias digitais, de acordo com Bacich, Tanzi Neto \& Trevisani (2015). No ensino híbrido existem quatro modelos principais: modelo de rotação; modelo flex; modelo à la carte; modelo virtual enriquecido.

No modelo de rotação, os estudantes revezam as atividades realizadas a partir de um horário fixo ou orientação do professor e a sala de aula invertida é utilizada neste modelo, em que os estudantes fazem atividades em formato on-line (aulas assíncronas) e utilizam o espaço da sala de aula para discussões (aulas síncronas). No modelo flex, a ênfase é no ensino on-line e o ritmo de cada aluno é personalizado e o professor fica à disposição para sanar dúvidas. No modelo à la carte, o estudante é o responsável pela organização de seus estudos. E no modelo virtual enriquecido, corresponde a uma experiência compartilhada por toda a escola, os alunos dividem o tempo entre aprendizagem on-line e presencial (BACICH, TANZI NETO \& TREVISANI, 2015).

Com o ato de deslocar a atenção do professor para o aprendiz e a aprendizagem surgiu a sala de aula invertida o que, segundo Bergmann \& Sams (2020), transformou a prática de ensino. Os referidos autores destacam que a ideia básica da aprendizagem para que os alunos alcancem uma série de objetivos no seu próprio ritmo foi popularizada por Benjamin Bloom, em 1960, com a aprendizagem para o domínio. 
A sala de aula invertida de aprendizagem para o domínio associa os princípios da aprendizagem para o domínio à tecnologia de informação para criar um ambiente de aprendizagem sustentável, replicável e gerenciável [...]. Basicamente, todos os alunos trabalham em tarefas diferentes, em momentos diferentes, empenhados e engajados na própria aprendizagem (BERGMANN e SAMS, 2020, p. 49).

Para utilizar-se da sala de aula invertida é necessário que os estudantes assumam um papel ativo e o professor passa a assumir uma postura de facilitador do processo de ensino e aprendizagem dos alunos, proporcionando autonomia e lhe dá a responsabilidade para adquirir conhecimentos (BACICH, TANZI NETO e TREVISANI, 2015).

Filatro \& Cavalcanti (2018) afirmam que Paulo Freire considera a autonomia um fator fundamental no processo de aprendizagem. Destaca-se que, segundo relatório Flipped Classroom Field Guide, de acordo com Bacich \& Moran (2018), as regras básicas para inverter a sala de aula são: as atividades devem envolver questionamento, resolução de problemas, aprendizagem ativa; os alunos devem receber feedback imediatamente após a realização das atividades presenciais; deve-se incentivar os alunos a participar das aulas on-line e presenciais, até para realizar a interação social; e, por fim, os materiais utilizados devem ser altamente estruturados e planejados.

A compreensão da interação social no processo de ensino e de conversão do conhecimento se trata, segundo Gomes (2021), à forma com que os discentes podem socializar os conhecimentos e internalizá-los, a fim de que se contemple, de forma completa, a conversão do conhecimento em aprendizagem. Assim, quando o modelo de ensino híbrido se utiliza da aprendizagem invertida, os alunos interagem com o material introdutório em casa antes de ir para a sala de aula, conforme Bergmann (2018). Tal material introdutório pode ser desenvolvido utilizando-se de tecnologias educacionais que, segundo Brito \& Purificação (2015) deve-se realizar a interação com o ambiente escolar no processo de ensino-aprendizagem em uso pelo professor na ação pedagógica. 


\section{Metodologia}

Sobre o histórico do PISA apresenta-se que em 1998 foram iniciadas as atividades para a aplicação do PISA no mundo, em 1999 foi aplicado pré-teste e a primeira edição foi em 2000. Destaca-se que o Brasil foi o primeiro país sul americano a aderir ao PISA e participam 4.893 jovens brasileiros, com idades entre 15 e 16 anos, o que consolidou os avanços já projetados no Sistema de Avaliação da Educação Básica (Saeb) e no Exame Nacional do Ensino Médio (Enem) (INEP, 2020).

As edições do PISA como estudo comparativo internacional realizado a cada três anos pela Organização para a Cooperação e Desenvolvimento Econômico (OCDE) ocorreram nos anos de: 2000, 2003, 2006, 2009, 2012 (início da aplicação por computador), 2015 (coleta de dados também com os professores) e 2018 (os pais de estudantes também participaram da pesquisa).

Segundo dados institucionais, no Brasil, o Sistema de Avaliação da Educação Básica, denominado de Saeb é de responsabilidade do INEP e compõe-se de duas avaliações externas: Avaliação Nacional de Alfabetização — ANA e Sistema Nacional de Avaliação do Ensino Superior — SINAES, sendo os resultados de tais avaliações utilizadas para calcular o Índice de Desenvolvimento da Educação Básica — Ideb, conforme França (2020).

O Saeb integra a Política Nacional de Avaliação da Educação Básica, do Ministério da Educação e utiliza dois tipos de instrumentos de coleta de dados: os testes cognitivos realizados com os discentes e os questionários aplicados com os docentes, diretores, secretários estaduais e municipais de educação.

Assim, diante do exposto apresenta-se o compilado dos resultados do PISA, ao longo dos anos, enfocando as primeiras colocações, sobre os três domínios: leitura, matemática e ciências, conforme a seguir: 
Quadro 1 - Resultados do PISA de 2000 até 2018 ( $1^{\circ}$ no ranking)

\begin{tabular}{|l|c|c|c|r|}
\hline \multicolumn{1}{|c|}{ País } & Leitura & Matemática & Ciências & \multicolumn{1}{c|}{$\begin{array}{c}\text { Somatório de } \\
\text { Notas }\end{array}$} \\
\hline Xangai (China) & 2009,2012 & 2009,2012 & 2009,2012 & 3.494 \\
\hline Finlândia & 2000,2003 & & 2003,2006 & 2.200 \\
\hline $\begin{array}{l}\text { Beijing, Shanghai, } \\
\text { Jiangsu, Zhejiang }\end{array}$ & 2018 & 2018 & 2018 & 1.736 \\
\hline Singapura & 2015 & 2015 & 2015 & 1.655 \\
\hline Coréia do Sul & 2006 & & 2000 & 1.108 \\
\hline Holanda & & 2000 & & 564 \\
\hline Hong Kong (China) & & 2003 & & 550 \\
\hline Taiwan (China) & & & 2006 & 549 \\
\hline
\end{tabular}

Fonte: dados da pesquisa (2021).

No último resultado apresentado do PISA 2015 e 2018 (os dois últimos) Xangai não ficou entre os dez mais pontuados no ranking e, por este motivo, não foi escolhido para este estudo para pesquisar o sistema de ensino, refletindo sobre a capacidade de que talvez não seja tão inovador e adaptado à realidade atual, o que cabe um estudo específico.

No PISA 2018 a Finlândia ficou na $7^{\mathrm{a}}$ posição para leitura e para ciências e no PISA 20015 ficou em $5^{\circ}$ lugar no ranking para ciências e no $4^{\circ}$ para leitura. Já Singapura, no PISA 2018, ficou em $2^{a}$ colocação para todos os domínios e no PISA 2015 ficou na $1^{a}$ colocação para todos os domínios. Já no PISA 2018 as províncias chinesas pela primeira vez ficaram dentro do ranking, alcançando o $1^{\circ}$ lugar conjuntamente, tendo por diferença entre Singapura, conforme quadro 1, o total de 81 pontos, considerando-se apenas a primeira posição.

Ao considerar o total de pontuação ao longo de todos os anos de PISA, Singapura detém maior posição no ranking dos dez primeiros colocados do que as referidas províncias chinesas, obtendo-se o total de 6.600 pontos, em contra partida, Beijing, Shanghai, Jiangsu, Zhejiang detém 1.736, pois apenas pontuaram para participar do ranking dos 10 primeiros colocados a partir do PISA 2018.

Diante do exposto, escolheu-se o sistema de ensino de Singapura para realizar a pesquisa considerando-se a representatividade ao longo dos anos do PISA, além dos rankings alcançados nos últimos PISA. Em relação aos procedimentos metodológicos adotou-se: pesquisa descritiva, exploratória, pesquisa documental e ensaio teórico, em 
que foram pesquisados os relatórios da OCDE sobre o PISA e documentos do Ministério da Educação de Singapura, disponibilizados nas suas plataformas.

Além disso, Singapura é reconhecida como um dos maiores centros financeiros do mundo, tendo investido largamente em educação. Destaca-se que o sucesso econômico de Singapura se deve, em parte, ao forte investimento social, especialmente em habitação saúde e educação. Segundo Wise (2021), culturalmente os singapurianos têm forte compromisso com o sucesso educacional e ganhou posições ao longo da aplicação do PISA. Em convergência, para a BBC News (2016) o sistema escolar enxuto de Singapura se beneficia do treinamento dos professores.

Justifica-se ainda a escolha por pesquisar sobre o sistema de ensino de Singapura pelo fato de que o país é considerado, atualmente, como o primeiro lugar no ranking de liberdade econômica e em competitividade, conforme dados do Heritage Foundation (2021), o que reflete o nível de prosperidade e de desenvolvimento social da população, que decorre também dos investimentos maciços em educação.

Assim, em relação a metodologia deste ensaio teórico destaca-se que foi adotada uma linha de raciocínio argumentativa, cujas reflexões visaram tirar conclusões de forma consciente e intencional, para a compreensão sobre o sistema de ensino de Singapura e para que fosse possível desenvolver um plano de ação para as Instituições de Ensino que oferecem o ensino híbrido, levando-se em consideração as variáveis, objetivos e ações que visam a melhoria dos resultados de aprendizagem.

Convém destacar que as fontes de coleta de dados foram: estudo de caso, análise dos dados do PISA, dados da Academia de Professores de Singapura sobre o sistema de ensino. Por corte temporal, este estudo compreendeu o período entre 2000 e 2019, já que os resultados do PISA 2018 só foram apresentados em 2019. O objeto de estudo foi o sistema de ensino de Singapura, tendo por unidade de análise a Academia de Professores. A natureza dos dados foi do tipo qualitativa a partir das análises das metodologias utilizadas na formação dos professores de Singapura e do tipo quantitativa ao coletar e analisar os dados do ranking PISA. 


\section{Plano de ação para o ensino híbrido}

Para Biesta et. al (2020), enquanto a tensão entre o desenvolvimento de programas de treinamento com o foco nos aspectos práticos do trabalho docente e o envolvimento com a teoria educacional e o fornecimento de bolsa de estudos não forem realizados de forma mais ampla será difícil atingir metas de ensino coletivamente responsáveis.

Nesse sentido, acredita-se que para melhorar os resultados da aprendizagem dos alunos, de maneira sistêmica, deve-se aprimorar o desenvolvimento profissional dos docentes, para tanto, a partir dos estudos realizados sobre o sistema de ensino de Singapura e o método híbrido, optou-se por desenvolver um plano de ação que poderá ser utilizado na educação profissional técnica e tecnológica com o modelo híbrido.

Convém ressaltar que a educação profissional técnica e tecnológica (EPT) é uma modalidade educacional prevista na Lei de Diretrizes e Bases da Educação Nacional (LDB) com a finalidade de preparar os estudantes para o exercício de profissões, de forma a contribuir para que o cidadão possa se inserir e atuar no mundo do trabalho e na vida em sociedade (MEC, 2021).

Nesse contexto, desenvolveu-se um plano de ação através de uma relação entre: as variáveis propostas pelo sistema de ensino de Singapura; os objetivos estabelecidos a partir das características propostas pala literatura sobre o ensino híbrido; e as ações a partir das análises e da proposta deste estudo, a fim de valorizar o conceito de ensino e aprendizagem se utilizando de tecnologias digitais na escola, possibilitando inclusive a personalização do ensino. 
Quadro 2 - Plano de Ação

\begin{tabular}{|c|c|c|}
\hline Variáveis & Objetivos & Ações \\
\hline $\begin{array}{l}\text { Educação para } \\
\text { educadores a partir } \\
\text { da } \quad \text { prática } \\
\text { profissional }\end{array}$ & $\begin{array}{l}\text { Valorizar a experiência } \\
\text { profissional dos professores } \\
\text { e alunos possibilitando } \\
\text { análise crítica e reflexiva das } \\
\text { atividades avaliativas. }\end{array}$ & $\begin{array}{l}\text { Utilização de jogos e de resolução de } \\
\text { problemas reais que incluam desafios e } \\
\text { apoio de profissionais da área, } \\
\text { integrando as tecnologias na educação } \\
\text { de modo criativo e crítico. }\end{array}$ \\
\hline $\begin{array}{l}\text { Educação orientada } \\
\text { para as políticas, } \\
\text { programas } \\
\text { práticas } \\
\text { educacionais e } \\
\text { escolares }\end{array}$ & $\begin{array}{l}\text { Possibilitar a troca de } \\
\text { experiências entre os } \\
\text { docentes potencializando a } \\
\text { relação professor-tecnologia } \\
\text { e a compreensão } \\
\text { socioemocional dos alunos. }\end{array}$ & $\begin{array}{l}\text { Integração dos ambientes virtuais de } \\
\text { aprendizagem entre os professores de } \\
\text { disciplinas do mesmo núcleo; } \\
\text { Utilizar nas práticas na sala de aula } \\
\text { (presencial ou on-line) estratégias de } \\
\text { aprendizagem individual e coletiva; } \\
\text { Realizar avaliações de forma } \\
\text { personalizada às turmas, favorecendo } \\
\text { momentos de integração e colaboração. }\end{array}$ \\
\hline $\begin{array}{l}\text { Visão do professor a } \\
\text { partir das } \\
\text { motivações } \\
\text { individuais }\end{array}$ & $\begin{array}{l}\text { Valorização dos saberes da } \\
\text { prática docente }\end{array}$ & $\begin{array}{l}\text { Realizar reuniões com o foco em } \\
\text { feedbacks continuados; } \\
\text { Participação em eventos para discussão } \\
\text { da prática docente, apresentando casos } \\
\text { de práticas de sucesso; } \\
\text { Criação de comunidades de de } \\
\text { aprendizagem em rede. }\end{array}$ \\
\hline $\begin{array}{l}\text { Compromisso dos } \\
\text { professores com a } \\
\text { docência }\end{array}$ & $\begin{array}{l}\text { Melhorar a qualidade do } \\
\text { processo de ensino- } \\
\text { aprendizagem através do } \\
\text { desenvolvimento } \\
\text { habilidades de } \\
\text { gerenciamento de sala de } \\
\text { aula }\end{array}$ & $\begin{array}{l}\text { Integração da sala de aula invertida em } \\
\text { suas práticas, promovendo o } \\
\text { engajamento dos alunos; } \\
\text { Professor como gestor de } \\
\text { aprendizagens múltiplas e complexas. }\end{array}$ \\
\hline $\begin{array}{l}\text { Guia de } \\
\text { planejamento e } \\
\text { feedback para o } \\
\text { processo de ensino }\end{array}$ & $\begin{array}{l}\text { Reflexão sobre processos de } \\
\text { aprendizagem e resultados } \\
\text { com avaliação e habilidades } \\
\text { de gerenciamento de sala de } \\
\text { aula }\end{array}$ & $\begin{array}{l}\text { Utilização de roteiros de aulas contendo } \\
\text { cronograma e lista dos conteúdos, além } \\
\text { de sugestões de vídeos para } \\
\text { complementação do processo de } \\
\text { ensino; } \\
\text { Ensino híbrido com foco em valores } \\
\text { como o projeto de vida dos alunos; } \\
\text { Compartilhamento de conquistas de } \\
\text { aprendizagem. }\end{array}$ \\
\hline
\end{tabular}

Fonte: autora da pesquisa (2021).

A estruturação de um plano de ação embasado em um conjunto de variáveis é um importante recurso ou ferramenta para atender a demanda da sala de aula e dos espaços virtuais de aprendizagem. Em convergência com Bacich, Tanzi Neto \& Trevisani (2015), acredita-se que é necessário repensar os espaços de aprendizagem, 
a maneira de produzir conteúdo e a formação dos professores a fim de possibilitar novas experiências aos alunos.

Em relação à variável educação para educadores a partir da prática profissional, que propõe a valorização da experiência, foi sugerida como ação a utilização de jogos e de resolução de problemas reais a exemplo da gamificação das atividades na sala de aula, com o uso, por exemplo, do mentimenter para coletar dados durante as aulas síncronas e iniciar as discussões dos conteúdos e inclusive para verificar a aprendizagem do coletivo. Destaca-se que tais sugestões correspondem à educação profissional técnica e tecnológica, o que se relaciona com a necessidade da aprendizagem focada na prática profissional.

$\mathrm{Na}$ variável educação orientada para as políticas, programas e práticas educacionais e escolares com o foco na troca de experiências entre os docentes, é sugerida a integração dos ambientes virtuais de aprendizagem entre os professores de disciplinas do mesmo núcleo, ou seja, o compartilhamento de materiais que serão utilizados nas aulas assíncronas entre docentes da mesma área e não apenas das mesmas disciplinas, favorecendo a interdisciplinaridade, além de colar em prática estratégias de aprendizagem individual e coletiva. Também realizar avaliações de forma personalizada às turmas por meio mentorias, chats e roteiros de ensino individualizados para cada disciplina.

Sobre a visão do professor a partir das motivações individuais para a valorização dos saberes da prática docente, recomenda-se realizar reuniões com o foco em feedbacks continuados, em que os docentes podem expor suas práticas na sala de aula, seja esta síncrona ou assíncrona, de forma a criar comunidades de aprendizagem em rede que focalizem práticas didáticas de efetivo sucesso junto à educação profissional técnica e tecnológica.

$\mathrm{Na}$ variável do plano de ação sobre compromisso dos professores com a docência para melhorar a qualidade do processo de ensino-aprendizagem propõe-se a integração da sala de aula invertida, além da atuação do professor como gestor de aprendizagens múltiplas e complexas, utilizando-se de técnicas como: alunos trabalhando em pequenos grupos ou individualmente; aplicação de avaliações formativas e somativas; respostas às avaliações utilizando tecnologias educacionais, com os PodCasts e gravação de vídeos interativos no YouTube. 
Na última variável proposta apresenta-se um guia de planejamento e feedback para o processo de ensino para reflexão sobre processos de aprendizagem e resultados, com avaliação e habilidades de gerenciamento de sala de aula, por meio de roteiros de aulas, detalhando os assuntos abordados de determinada disciplina, a fim de nortear o estudo dos alunos. Também se sugere a realização de um projeto integrador de identidade e apropriação com foco em valores como o projeto de vida dos alunos da educação profissional técnica e tecnológica objetivando o desenvolvimento profissional.

Também se sugere o compartilhamento de conquistas de aprendizagem, incentivando o desenvolvimento socioemocional e o de competências a partir da disseminação de informações sobre o processo de ensino e aprendizagem e, inclusive, com a criação de grupos de trabalho, valorizando mais a colaboração do que a competição.

\section{Considerações finais}

Os princípios do sistema de ensino de Singapura focalizam principalmente na valorização dos docentes e em um modo de aprendizagem em comunidades de aprendizagem profissional colaborativa. Nesse sentido, pode-se utilizar um modelo de educação híbrido a partir dos princípios adotados pelos melhores sistemas de ensino do mundo, de acordo com o Programa Internacional de Avaliação de Alunos - PISA, através de ações que contemplem as metodologias ativas.

Nesse sentido, destaca-se que para promover a efetiva valorização dos professores em nossa realidade, entre outros fatores, ainda faltam programas de formação continuada para os educadores brasileiros, disponibilizados a partir das instituições de ensino demandantes. Pois, percebe-se que, em muitas instituições os docentes que vão à busca de sua própria capacitação estão, na maioria das vezes, motivados apenas pela valorização salarial na pós-capacitação.

Sugere-se a recepção constante do feedback dos alunos, dos pais e da comunidade, ouvir mais, como um ato descentralizado, e não como parte de uma reunião de gestão. Recomenda-se também ouvir mais a base do processo, os docentes, valorizar mais a base do processo, reconhecer suas dificuldades e incapacidades, a fim 
de discutir sobre o ensino e abordagens pedagógicas e o próprio gerenciamento de sala de aula.

Ao final, acredita-se que com um plano de ação para colocar em prática durante o ensino híbrido será possível desenvolver uma prática reflexiva que focalize a construção de conexões e que permita aos docentes compartilhar e planejar seus próprios objetivos de aprendizagem, sendo que a criação de comunidades de aprendizagem profissional em rede também pode promover o aprendizado de forma colaborativa.

\section{Referências}

ACADEMY OF SINGAPORE TEACHERS. Singapore Teaching Practice (STP). Disponível em: https://academyofsingaporeteachers.moe.edu.sg/professional-excellence/thesingapore-teaching-practice. Acesso em: 02 jan. 2021.

ABREU, J. C. F. Construção e Gestão de Materiais Pedagógicos no Ensino da Matemática: uma adaptação do Método de Singapura no contexto da Educação Pré-Escolar e do $1{ }^{\circ}$ Ciclo do Ensino Básico. Relatório de estágio para o grau de Mestre em Educação. Ponta Delgada: Universidade dos Açores, 2017.2 Disponível em: https://repositorio.uac.pt/handle/10400.3/4645. Acesso em: 24 fev. 2021.

BACICH, L.; MORAN, J. (orgs.). Metodologias ativas para uma educação inovadora - uma abordagem teórico-prática. Série Desafios da Educação. Porto Alegre: Penso, 2018.

BACICH, L.; TANZI NETO, A.; TREVISANI, F. M. (orgs.). Ensino bíbrido: personalização e tecnologias na educação. Porto Alegre: Penso, 2015.

BBC NEWS. Os segredos de Cingapura, apontado como o país com a melhor educação do mundo. 2016. Disponível em: https://www.bbc.com/portuguese/internacional-38220311. Acesso em: 02 out. 2021.

BERGMANN, J. Aprendizagem invertida para resolver o problema do dever de casa. Porto Alegre: Penso, 2018.

BERGMANN, J.; SAMS, A. Sala de aula invertida: uma metodologia ativa de aprendizagem. Rio de Janeiro: LTC, 2020.

BIESTA, G. et. al. Formação de professores entre princípio, política e prática: uma declaração dos novos editores do Asia-Pacific Journal of Teacher Education. Asia-Pacific Journal of Teacher Education, v. 48, n. 20, p. 455-459, 2020. https://doi.org/10.1080/1359866X.2020.1818485.

BRASIL. Lei de no 9.394 de Diretrizes e Bases da Educação Nacional, de 20 de dezembro de 1996. Disponível $\mathrm{em}:$ http://www.planalto.gov.br/ccivil_03/leis/19394.htm\#: :text=L9394\&text=Estabelece\% 20 as $\% 20$ diretrizes $\% 20 \mathrm{e} \% 20$ bases $^{2} \% 20 \mathrm{da} \% 20$ educa $\% \mathrm{C} 3 \% \mathrm{~A} 7 \% \mathrm{C} 3 \% \mathrm{~A} 3 \mathrm{o} \% 20$ nacional.\&text 
$=$ Art.,civil $\% 20 \mathrm{e} \% 20$ nas $\% 20$ manifesta $\% C 3 \%$ A7\% $\%$ C3\%B 3 es $\% 20$ culturais. Acesso em: 01 nov. 2020.

BRITO, G. S.; PURIFICAÇÃO, I. Educação e novas tecnologias: um repensar. Curitiba: Intersaberes, 2015.

ELOS EDUCACIONAL. O que a educação pública de Singapura pode nos ensinar? 2019. Disponível em: https://www.eloseducacional.com/educacao/o-que-a-educacao-publica-desingapura-pode-nos-ensinar/. Acesso em: 08 mar. 2021.

FILATRO, A.; CAVALCANTI, C. C. Metodologias inov-ativas na educação presencial, a distância e corporativa. São Paulo: Saraiva, 2018.

FRANÇA, L. SAEB: Sistema de avaliação da educação básica. Par Plataforma Educacional, 2020. Disponível em: https://www.somospar.com.br/saeb/. Acesso em: 10 jan. 2021.

FUNDAÇÃO LEMANN. Caravana da Educação em Singapura - Lemann Fellows e Talentos da Educação foram até o país número 1 no PISA para conhecer suas políticas públicas educacionais. 2020. Disponível em: https://fundacaolemann.org.br/noticias/caravana-daeducacao-em-singapura. Acesso em: 26 dez. 2020.

GOMES, A. F. et. al. Ensino remoto da área técnica de administração para a conversão do conhecimento: relato de experiência de ensino, durante a pandemia, nos cursos técnicos em administração do Instituto Federal de Educação, Ciência e Tecnologia Baiano - campus Teixeira de Freitas. In: SILVA, C. R. M. (org.). Administração: ciência e tecnologia, estratégia, administração pública e estudos organizacionais. 2021. Ponta Grossa: Atena. p. 244-255. doi $10.22533 /$ at.ed.84721100318.

HERITAGE FOUNDATION. Singapore. 2021. Disponível em: https://www.heritage.org/index/country/singapore. Acesso em: 02 out. 2021.

INEP. Programa Internacional de Avaliação de Estudantes (Pisa). 2020. Disponível em: https://www.gov.br/inep/pt-br/areas-de-atuacao/avaliacao-e-exames-educacionais/pisa. Acesso em: 26 dez. 2020.

JACKSON, D.; TEMPERLEY, J. From Professional Learning Community to Networked Learning Community. In: International Congress for School Effectiveness and Improvement (ICSEI). Conference. 2006. Fort Lauderdale: National College for School Leadership, 2006. Disponível em: https://www.innovationunit.org/wpcontent/uploads/2017/04/From-professional-learning-community-to-networked-learningcommunity.pdf. Acesso em: 15 fev. 2021.

MCCONNELL, T. J. et. al. Virtual professional learning communities: Teachers' perceptions of virtual versus face-to-face professional development. Journal of Science Education and Technology, v. 22, p. 267-277, 2013. doi https://doi.org/10.1007/s10956-012-9391-y. Disponível em: https://link.springer.com/article/10.1007/s10956-012-9391-y. Acesso em: 01 mar. 2021.

MEC. Educação profissional e tecnológica (EPT). Disponível em: http://portal.mec.gov.br/educacao-profissional-e-tecnologica-ept. Acesso em: 12 fev. 2021. 
MOREIRA, A.; LOPES, A. O que a Educação pública de Singapura pode nos ensinar? Elos Educacional, 2019. Disponível em: https://www.eloseducacional.com/educacao/o-que-aeducacao-publica-de-singapura-pode-nos-ensinar/. Acesso em: 02 jan. 2021.

NATIONAL INSTITUTE OF EDUCATION. Teacher education. Disponível em: https://www.nie.edu.sg/teacher-education/. Acesso em: 03 jan. 2021.

NIE. Certificate in Teaching and Learning for Community Educators. About the programme. Disponível em: https://www.niei.nie.edu.sg/programmes-courses/accreditation-coursesaward-programmes/certificate-teaching-and-learning-communit. Acesso em: 06 jan. 2021.

PORTUGAL. Embaixada de Portugal em Singapura. Disponível em: https://singapura.embaixadaportugal.mne.gov.pt/pt/sobre-singapura/dados-gerais. Acesso em: 27 dez. 2020.

SILVA, H. B. P. Análise comparada da estrutura curricular do curso de pedagogia em duas instituições: Universidade de Brasília e Instituto Nacional de Educação de Singapura. Trabalbo final de curso (Licenciatura em Pedagogia), Universidade, Brasília: UNB, 2011. Disponível em: https://bdm.unb.br/bitstream/10483/3152/1/2011_HelaineBeatrizPereiradaSilva.pdf.

Acesso: 08 mar. 2021.

SINGAPORE. Ministry of education. Singapore teacher academy. 2020. Disponível em: <https://www.sgdi.gov.sg/ministries/moe/departments/ast>. Acesso em: 12 dez. 2020.

SOARES, K. C. D. SOARES, M. A. S. Sistemas de ensino: legislação e política educacional para a educação básica. Curitiba: Intersaberes, 2017.

WISE, A. Cingapura é líder em educaşão - Mas é melhor não seguir todos os seus métodos. Gazeta do povo, 2021. Disponível em: https://www.gazetadopovo.com.br/educacao/ cingapura-e-lider-em-educacao-mas-emelhor-nao-seguir-todos-os-seus-metodos-cbfqpf914rxy816z9e6736av0/. Acesso em: 02 out. 2021.

RECEBIDO: $21 / 03 / 2021$

APROVADO: 20/10/2021

RECEIVED: 03/21/2021

APPROVED: $10 / 20 / 2021$

RECIBIDO: $21 / 03 / 2021$

APROBADO: 20/10/2021 